that patients with severe psychosis may be dramatically medication-resistant, unless they have used threshold dosing they do not know that the sensitivity of the patient to antipsychotic medication increases as their mental state improves, allowing a reduction in dose with maintained efficacy. It is worth remembering that BNF limits are usually established in accessible and responsive out-patient populations with moderate symptoms. Practising clinicians treat many patients who do not come from this population and may find themselves with a difficult choice: polypharmacy or prescription outside $B N F$ limits.

1 Taylor D. Antipsychotic polypharmacy - confusion reigns. Psychiatrist 2010; 34: 41-3.

2 Agid O, Mamo D, Ginovart N, Vitcu I, Wilson AA, Zipursky RB, et al. Striatal vs extrastriatal dopamine $D 2$ receptors in antipsychotic response - a double-blind PET study in schizophrenia. Neuropsychopharmacology 2006; 32: 1209-15.

3 Searle GF. Optimising neuroleptic treatment for psychotic illness. Psychiatr Bull 1998; 22: 548-51.

Geoffrey F. Searle is Consultant Psychiatrist, Dorset Healthcare NHS Foundation Trust, UK, email: geoff.searle@dhft.nhs.uk

doi: $10.1192 / \mathrm{pb} .34 .6 .259 \mathrm{~b}$

\section{The importance of early and accurate diagnosis}

The excellent article by Chan \& Sireling ${ }^{\top}$ about the recent increase in public awareness of bipolar disorder mirrors our own experience in research and practice, and highlights important issues for health services.

This article is very timely because there is ongoing debate about the extent to which bipolar disorder may be over- or underdiagnosed. ${ }^{2,3}$ Both over- and underdiagnosis occur and are problematic. Some people may be inappropriately labelled, whereas others who would benefit from the diagnosis are missed. Optimal treatment of depression is different in bipolar and unipolar disorders. This is one of many examples in psychiatry where making an early and correct diagnosis is highly likely to have a very direct and important effect on the quality of care offered to, and quality of life experienced by, a patient. ${ }^{4}$

Chan \& Sireling highlight new cases of bipolar disorder from the primary care setting. Preliminary data from our ongoing studies of primary care patients with depression suggest that bipolar (i.e. manic/hypomanic) features are relatively common in this group (unpublished data; available from the authors on request). In our wider research in individuals with both bipolar and unipolar mood disorders, we have found that those with a diagnosis of recurrent unipolar depression who have a history of mild manic symptoms tend to respond less well to antidepressants. ${ }^{5}$

Inevitably, increasing awareness of any illness has the potential to lead to overdiagnosis and this could cause problems for the patient as well as for services. Thus, a balance must always be struck between the need to increase awareness appropriately among patients, public and clinicians, while not causing a tsunami of uncritical overdiagnosis and self-labelling. As psychiatrists we must ensure we are pragmatic and put the patient's well-being at the centre of decision-making. This will require us to have knowledge of the developing evidence base, make a comprehensive diagnosis based on a detailed lifetime history of both depressed and manic mood (including asking an informant), and have an awareness of the boundaries of clinically relevant symptomatology.

1 Chan C, Sireling L. 'I want to be bipolar' ... a new phenomenon. Psychiatrist 2010; 34: 103-5.

2 Zimmerman $M$. Is underdiagnosis the main pitfall in diagnosing bipolar disorder? No. BMJ 2010; 340: c855.

3 Smith DJ, Ghaemi N. Is underdiagnosis the main pitfall when diagnosing bipolar disorder? Yes. BMJ 2010; 340: c854.

4 Craddock N, Antebi D, Attenburrow MJ, Bailey A, Carson A, Cowen P, et al. Wake-up call for British psychiatry. Br J Psychiatry 2008; 193: 6-9.

5 Smith DJ, Forty L, Russell E, Caesar S, Walters J, Cooper C, et al. Subthreshold manic symptoms in recurrent major depressive disorder are a marker for poor outcome. Acta Psychiatr Scand 2009; 119: 325-9.

Nick Craddock is Professor of Psychiatry, Ian Jones is Senior Lecturer in Perinatal Psychiatry and Daniel J. Smith is Senior Lecturer in Psychiatry, Department of Psychological Medicine and Neurology, School of Medicine, Cardiff University, UK, email: craddockn@cardiff.ac.uk

doi: $10.1192 / p b .34 .6 .260$

\section{The suggested obligation to declare mental health issues to employer}

I enjoyed Chan \& Sireling's article ${ }^{1}$ considerably, although | must write in response to the comments about obligatory declarations of mental health to employers.

Although there is little doubt that in most cases employers need to be aware of a bipolar affective condition in employees, this is not always appropriate. Indeed, best practice requires employers to require submission of preemployment forms not to themselves but to an occupational health professional. Those with a bipolar condition should almost always be invited to a review with an occupational physician.

At that point, and that point only, is it appropriate for there to be discussion as to what is to be shared with the employer. At the very least such a consultation is likely to head in the direction of advice to an employer that the employee has a condition which may require adjustment under the Disability Discrimination Act. What an occupational physician tells an employer is, however, subject to their own professional judgement and indeed ultimately down to what the employee feels is appropriate.

Occupational medicine is a small specialty, although a valuable one, not least for psychiatric patients, for whom we can do a great deal.

1 Chan C, Sireling L. 'I want to be bipolar' ... a new phenomenon. Psychiatrist 2010; 34: 103-5.

Clive H. Morgan is Occupational Physician, Cardiff, UK, email: chmorgan@doctors.org.uk

doi: 10.1192/pb.34.6.260a

\section{Narrative triad and philosophy}

Wallang ${ }^{1}$ provides a stimulating and insightful consilience of wide-ranging ideas. This is what a journal should be about, not the repetitive reductive statistics cobbled together to further 
careers rather than knowledge. The traditional splitting of organic, phenomenological and analytic approaches is rarely appropriately addressed without reference to philosophy and culture; and then usually in an entrenched and divisive manner. Dr Wallang's very constructive syncretism, described in terms of the narrative triad, is a literate and absorbing one. Can we not give more prominence to such informed articles which enrich debate rather than burying it in computation?

1 Wallang P. Wittgenstein's legacy and narrative networks: incorporating a meaning-centred approach to patient consultation. Psychiatrist 2010; 34: 157-61.

Anthony John Warren Consultant Psychiatrist (retired), Cygnet Healthcare, London, UK, email: cygnetdoc@aol.com

doi: $10.1192 / p b .34 .6 .260 b$

\section{Anyone for critical psychiatry?}

An admissions tutor in my medical school interview poured a helping of caution on my wary expression of interest in psychiatry. 'That often changes after your rotation in it,' he quipped, as if this was an old medical education in-joke.

Now sampling some 'real medicine' as the hackneyed jibe goes, I am still digesting my psychiatry rotation. I am starting to see how psychiatry's relationship with medicine is fraught with unrequited love. The tender issues of identity related to this are all too plain for undergraduate students to see. In his masterful anthropological survey of a London medical school in the nineties, ${ }^{1}$ Sinclair remarks that the stigma attached to psychiatry and the profession's dubious ranking on the hierarchy of specialty 'sex appeal' are part of the informal curriculum. That this subtext is so deeply entrenched to show itself to one potential psychiatrist before even starting medical school is a sign of how great a challenge the Royal College of Psychiatrists faces in boosting recruitment.

One approach would be to incorporate an element of critical psychiatry into the undergraduate curriculum. For those at the helm of the profession's recruitment efforts giving space for dissent might seem counter-intuitive. However, such a strategy might resonate strongly with those students whose response to their first experience of psychiatry was largely negative. Encouraging discussion conducive to critical thought might protect against marginalising their experience as nonconformist and so inconsistent with pursuing a career in the specialty. It would allow them to see that their instinctive doubts as to the efficacy of the profession's pharmacopoeia and its biological reductionism are shared and hotly debated by many at the top of the profession. In addition, it might serve as an early lesson in the value of tolerating ambiguity and uncertainty, transforming the clichéd critique of 'wooliness' levelled at psychiatry into something richer in possibility.

An awareness of the critical psychiatry movement and the culture war within the profession would give students a more favourable portrait of the specialty's willingness to engage with and accommodate dissenting voices. Undergraduates deserve being granted a broader perspective with which to make sense of their responses to psychiatry and more effectively challenge its epistemological frailties. With a more sophisticated understanding of the forces and philosophical concerns underpinning the profession, those deciding to join its ranks might be in a stronger position to more meaningfully participate in its evolution.

1 Sinclair S. Making Doctors: An Institutional Apprenticeship (Explorations in Anthropology). Berg Publishers, 1997.

Jonny Martell is medical student, King's College London School of Medicine, UK, email: jonny.martell@kcl.ac.uk

doi: $10.1192 / p b .34 .6 .261$

\section{Hospital transfers need proper assessment}

Wilson et al highlight the delays in transferring prisoners to hospital, including a suggestion that a 'postcode lottery' operates. Although we agree with much of the article, we would contest the statement that 'Given the extensive development of mental health in-reach services, and the fact that referrals are made by senior psychiatrists, it seems surprising that it has become routine for receiving units to undertake their own assessment, apparently duplicating work.'

Clearly, it is important that the transfer of mentally ill prisoners needing hospital treatment is expedited and this is no doubt a view shared by both prison psychiatrists and those in the receiving units. However, although this is the main concern of prison psychiatrists, receiving units also have to consider the appropriateness of the placement and issues of risk.

Furthermore, it is not always the case that referrals are made 'by senior psychiatrists'. And regardless of the author of the referral, assessment by a receiving unit provides an opportunity for additional and often significant information to be collected. This enables the unit to carefully consider risk issues and prepare for a safe admission to an appropriately secure unit, an issue highlighted by the core Never Events relating to escape from medium or high secure units. ${ }^{2}$ Sometimes this more properly informed assessment clarifies that a prisoner does not need transfer for treatment. This was highlighted in the sensible guidance from the Department of Health, ${ }^{3}$ which distinguished between routine and urgent referrals, allowing assessments to be appropriately prioritised.

Given that beds are usually at a premium in secure services, simply accepting every prison referral would lead to even further unacceptable pressure on beds and perversely exacerbate the very problem Wilson et al seek to address.

\section{Declaration of interest}

O.C. and G.D. work equal time between a London remand prison and on secure admission wards.

1 Wilson S, Chiu K, Parrott J, Forrester A. Postcode lottery? Hospital transfers from one London prison and responsible catchment area. Psychiatrist 2010; 34: 140-2.

2 National Patient Safety Agency. Never Events. NPSA, 2009 (http:// www.nrls.npsa.nhs.uk/resources/collections/never-events/).

3 Department of Health. Best Practice Guidance: Specification for Adult Medium-Secure Services. Department of Health, 2007.

Oriana Chao and Gary Duffield are Consultant Forensic Psychiatrists working at the North London Forensic Service, UK, email: oriana.chao@enfield.nhs.uk

doi: $10.1192 / p b .34 .6 .261 a$ 